\title{
On the evaluation of yield stress of soils for debris flow analysis
}

\author{
Carlos Besso ${ }^{1, *}$ and Tácio Mauro Pereira de Campos ${ }^{1}$ \\ ${ }^{1}$ Pontíficia Universidade Católica do Rio de Janeiro, Department of Civil and Environmental Eng., Brazil
}

\begin{abstract}
Debris flow materials behave as a fluid, hence its analysis requires rheological parameters such as yield stress and viscosity. Yield stress is associated to the start and the end of the mass movement downhill in the sense that it denotes the yield transition from the creep to the flow regime, i.e., passage from solid to fluid state. This paper presents an experimental study of the yield stress of a colluvium from Rio de Janeiro, through its determination in a modified set-up of the slump test and in a rotational parallel plate rheometer. Tests were performed in five different water contents above its liquidity limit, providing a fairly good relationship between yield stress and water content. While slump test provides yield stress related to the beginning of the movement (acceleration), rheometer results are related to flow's outset and stoppage. As a result, the percentual differences between yield stresses associated with acceleration and deceleration were less than $5 \%$ in all testes, which is related to the low hysteresis effect in the flow curves obtained in the rotational rheometer. Comparing the two methodologies, it is proposed a correction from rheometer to slump test results. Results obtained are compared with data presented in other studies involving soil's yield stress, showing a good acceptance of the slump test results as a cheap alternative to rheometers.
\end{abstract}

\section{Introduction}

Debris flow comprises one of the most damaging movements among landslides (de Campos \& Galindo [1]). Its propagation along drainage channels is associated with high velocities and wide areas of deposition. Few studies have been taken on investigations on how the rheological parameters of the descendent material influence its mechanical behaviour such as velocity, force impact and extent of deposition.

Some researches have been taken in the last few decades on analyses of the viscosity and the yield stress of soil-water mixtures (e.g., de Campos \& Galindo, di Santolo et al., Jeong, O'Brien \& Julien, Galindo, Coussot \& Piau, Jeong, Roussel \& Coussot [1-8]), usually correlating one or the two parameters with the solid volumetric concentration of the mass, which for saturated soils is defined by expression 1 .

$$
C_{v}=\frac{V_{s}}{V}=\frac{1}{1+w \cdot G_{s}}
$$

Where $C_{v}$ is the solid volumetric concentration, $V_{s}$ is the solid volume, $V$ is the total volume, $w$ is the water content and $G_{s}$ is the specific gravity of the grains. It should be noted that water content and solid concentration present an inverse relation.

This study intends to improve the understanding of the rheological behaviour of tropical soils over an experimental study of the yield stress of a colluvium from Rio de Janeiro/Brazil, through its determination in a modified set-up of the slump test and in a rotational parallel plate rheometer. Moreover, it is intended to evaluate the efficiency of the test as an alternative to expensive rheometric equipment.

\section{Yield stress}

In a flow curve of fine-grained sediments (Figure 1), there is a yield transition from creep regime (rapid increase of shear stress due to low increments of shear rate) to the flow regime (where flow is established and shear stress develops less considerable variations along time). This transition from solid-type material to fluid-type is denoted by the yield stress.

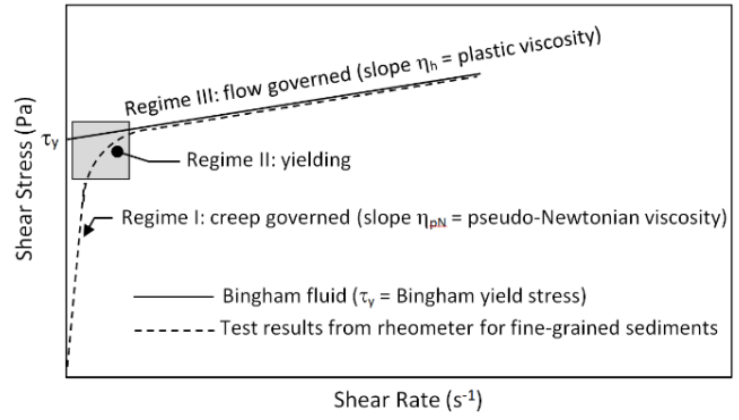

Fig. 1. Typical flow curve for soil-water mixtures (adapted from Jeong [2]).

In the present study it is discussed some aspects of yield stress and its possible relations to debris flow phenomena involving tropical soils.

\footnotetext{
* Corresponding author: carlosbesso@,outlook.com
} 


\section{Tested material}

The analysed material comprises a widely studied colluvium from a natural slope within the main campus of Pontifícia Universidade Católica do Rio de Janeiro (PUCRio), denoted MCP. The material has no background of relevant mass movement and it was unsaturated under its original condition (de Campos \& Galindo [1]).

Figure 2 and Tables 1 and 2 show the physical and mineralogical characterization of MCP soil. Conventional geotechnical characterization tests were performed in the Brazilian standards. Mineralogical analyses were performed using both differential thermal analysis and Xray diffraction (Table 2). The soil is a clayey-sand material, and is classified as a high-plasticity clay according to USCS.

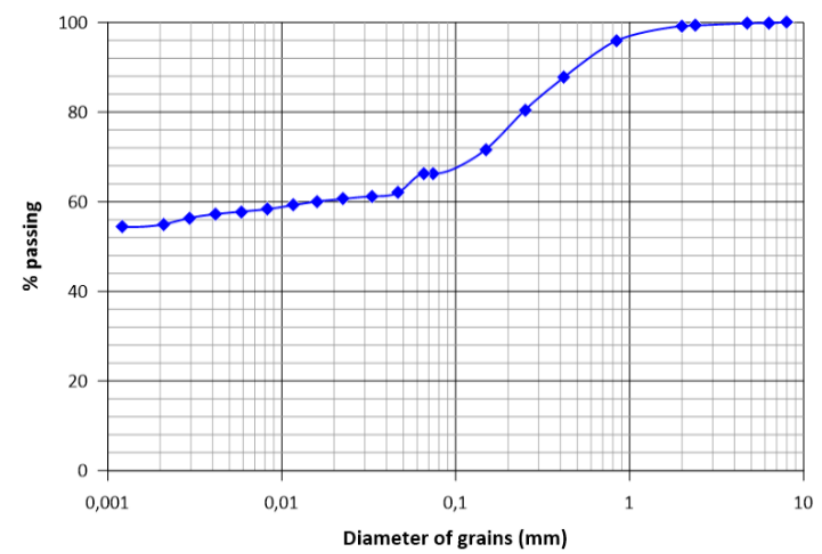

Fig. 2. Grain size distribution of the MCP soil.

The sedimentation test was realized in presence of sodium hexametaphosphate deflocculant, thus it is important to note that it has been observed changes in the grain size distribution when the test was realized using water. The clay fraction disappeared and its particles formed silt to fine sand sized clusters (de Campos \& Galindo [1]). This finding is relevant in the sense that all mechanical tests in this study were realized with water, and debris flow mechanisms may change depending on the grain size of the moving mass (e.g. di Santolo et al., Jeong $[3,4])$.

Table 1. Percentual grain size fractions.

\begin{tabular}{|c|c|c|c|}
\hline Gravel (\%) & Sand (\%) & Silt (\%) & Clay (\%) \\
\hline 0.8 & 34.1 & 10.2 & 54.9 \\
\hline
\end{tabular}

Table 2. Physical and mineralogical characterization of the MCP soil.

\begin{tabular}{|c|c|c|c|c|c|c|}
\hline $\begin{array}{c}\text { LL } \\
(\%)\end{array}$ & $\begin{array}{c}\text { LP } \\
(\mathbf{\%})\end{array}$ & $\begin{array}{c}\text { PI } \\
(\mathbf{\%})\end{array}$ & $\mathbf{A c}_{\mathbf{c}}$ & $\mathbf{G s}$ & $\begin{array}{c}\text { Clay } \\
\text { mineral }\end{array}$ & USCS \\
\hline 68.0 & 28.3 & 39.7 & 0.72 & 2.723 & Kaolinite & $\mathrm{CH}$ \\
\hline
\end{tabular}

\section{Equipment and procedures}

\subsection{Slump test}

The modified slump test set-up used in this study is shown in Figure 3 and its particularities are well explained in Galindo [6]. Tests consists in uplifting the truncated cone by loading an extra weight to the counter weight (located in the left size of the equipment), as shown in Figure 4.

In order to minimize surface friction effects between the mass and the internal cone surface, it was used a thin layer of glycerine as lubricant. Furthermore, the counter weight was loaded with $20 \mathrm{~kg}$ to speed the cone uplift, hence the mass-cone contact was minimized during the test.

The tests were performed in an environmental controlled room at a temperature of $221{ }^{\circ} \mathrm{C}$. The final diameter, the soil mass and water content were measured at the end of each test, and the yield stress is calculated according to the proposal by Roussel \& Coussot [9], shown in Equation 2

$$
\tau_{0}=\frac{225 \cdot \rho \cdot g \cdot V^{2}}{128 \cdot \pi \cdot D^{5}}
$$

where $\tau_{0}$ is the yield stress, $\rho$ is the material's specific weight, $g$ is the acceleration of gravity, $V$ is the material's volume, and $D$ is the material's diameter at the end of the test.

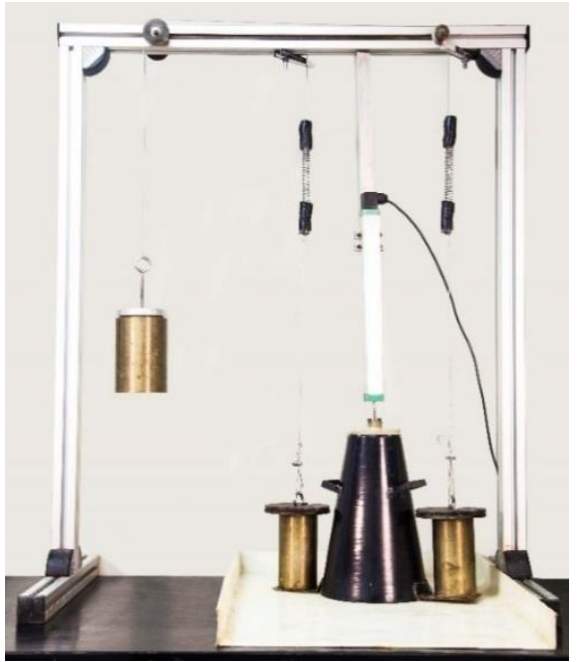

Fig. 3. Modified slump test set-up.
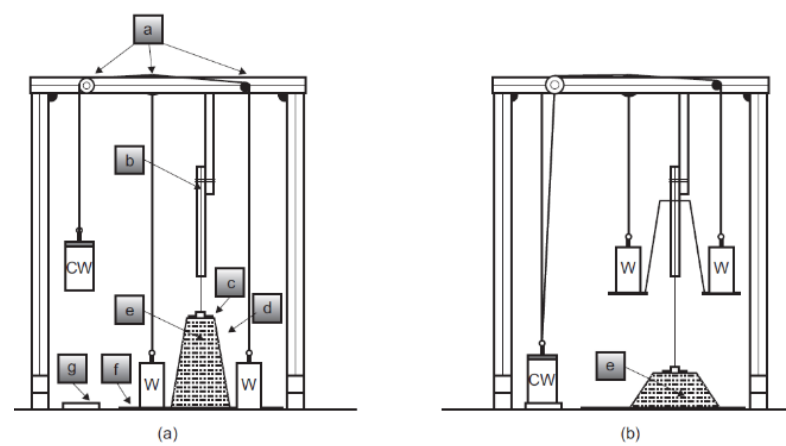

Fig. 4. Scheme of the slump test, before (a) and after (b) the test (de Campos \& Galindo [1]). 


\subsection{Rheometer}

Flow ramp tests (or sweep tests) were performed in a plate-plate geometry in the rotational rheometer Discovery, shown in Figure 5. Those tests are deformation-controlled type, where the shear rate of the equipment is incrementally increased/decreased, and the shear stress is determined with the measured torque, according to Equation 3.

$$
\tau=\frac{2 \cdot M}{\pi \cdot R^{3}}
$$

Where is the shear stress, $M$ is the measured torque and $R$ is the plate radius. As it is suggested in O'Brien \& Julien [5], tests were realized in a gap of shear rates commonly observed in debris flows materials (from 0,1 to $\left.100 \mathrm{~s}^{-1}\right)$.

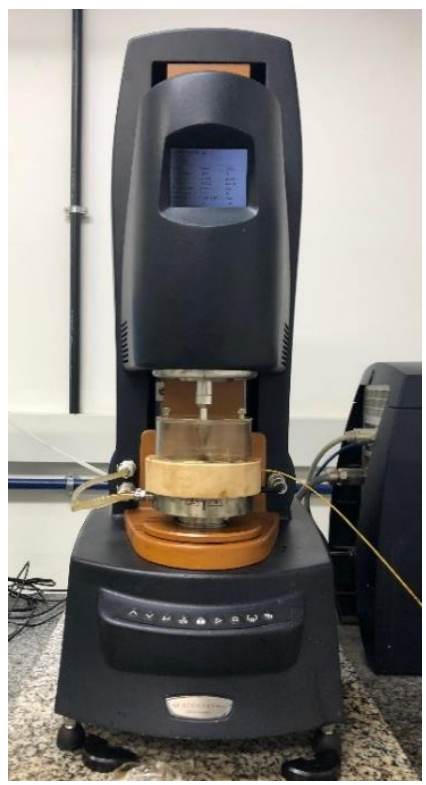

Figure 5. Discovery rotational rheometer.

To investigate the occurrence of hysteresis phenomena in the flow curves of the MCP soil, sweep tests were realized, uninterruptedly, in acceleration (shear rate increasing) and deceleration ramps. To avoid material sedimentation and drying, tests had a total duration of $120 \mathrm{~s}$ and samples thickness was set to $2 \mathrm{~mm}$. In order to follow the same conditions as the slump tests, a controlled temperature of $22{ }^{\circ} \mathrm{C}$ was imposed to all the tests.

\section{Results and discussions}

\subsection{Flow curves}

The flow curves herein obtained are presented in Figure 6. It can be firstly noted that a creep regime is established in the beginning of the acceleration ramp, where the material behaves as a solid (low increases in shear rate are associated with rapid increase of shear stress), followed by a flow regime after yield stress is reached (a stress plateau is established). As a certain shear rate is passed, a new interval where shear stress turns to increase is observed, until the deceleration ramp begins and a second yield stress is noted whereas shear rate decrease causes no significant variation in shear stress.

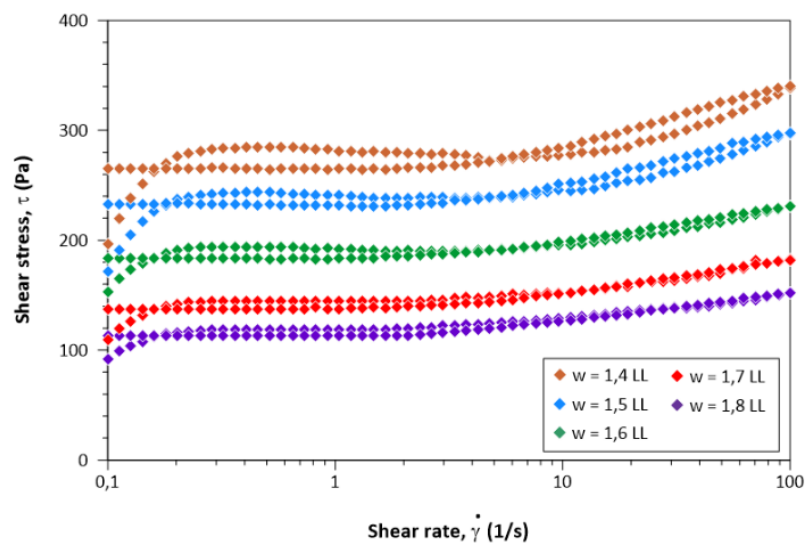

Fig. 6. Flow curves obtained in the rotational rheometer.

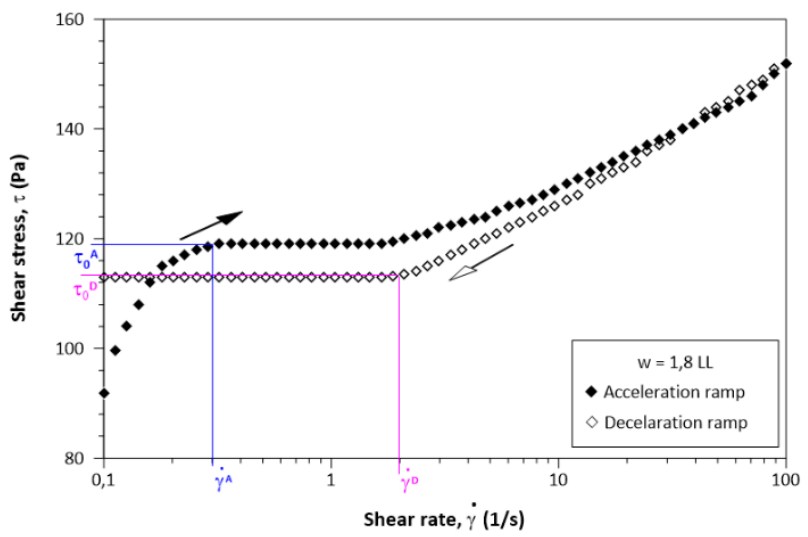

Fig. 7. Yield stress obtention criteria in acceleration and deceleration ramps.

It can be noticed that little hysteresis effect occurs in the material, though its magnitude decreases with water content growth. This phenomenon is possibly related to a fragile arrange of the grains-water structure, leading to a irreversible collapse due to large deformations. Hysteresis influence in the yield stresses associated to flow outset and stoppage was analysed by calculating the percentual difference between the two stresses (Table 3 ).

Table 3. Yield stresses and its percentual difference, obtained in acceleration and deceleration flow ramp tests performed in the rotational rheometer.

\begin{tabular}{|c|c|c|c|}
\hline $\mathbf{w} / \mathbf{L L}$ & $\begin{array}{c}\tau_{\mathbf{0}} \text { acceleration } \\
(\mathbf{P a})\end{array}$ & $\begin{array}{c}\tau_{\mathbf{0}} \text { deceleration } \\
(\mathbf{P a})\end{array}$ & $\begin{array}{c}\mathbf{\%} \\
\text { difference }\end{array}$ \\
\hline 1.4 & 284 & 266 & 6 \\
\hline 1.5 & 243 & 232 & 5 \\
\hline 1.6 & 194 & 185 & 5 \\
\hline 1.7 & 145 & 140 & 3 \\
\hline 1.8 & 118 & 116 & 2 \\
\hline
\end{tabular}

Representation of the adopted criteria to yield stress determination is shown in Figure 7, exemplified in the 
flow curve of the sample with 1,8LL water content. It was observed that for all samples, the yield stresses related to acceleration and deceleration ramps were reached at a shear rate around 0.3 and $2.0 \mathrm{~s}^{-1}$, respectively. It is noticed that the higher the water content, the lower the percentual differences between the two stresses.

\subsection{Yield stress}

Yield stresses obtained in the rheometer and in the slump test, as well as sample's water content and solid concentration, are shown in Table 4. Comparisons between stresses obtained in the slump tests and in the rheometer (this last associated with acceleration flow ramps) are presented in Figures 8, 9 and 10.

Table 4. Yield stress obtained in rheometer and slump test

\begin{tabular}{|c|c|c|c|c|c|}
\hline $\begin{array}{c}\mathbf{W} \\
\mathbf{( \% )}\end{array}$ & $\mathbf{w} / \mathbf{L L}$ & $\begin{array}{c}\mathbf{C}_{\mathbf{v}} \\
\mathbf{( \% )}\end{array}$ & $\begin{array}{c}\tau_{\mathbf{0}}^{\text {rheometer }} \\
(\mathbf{P a})\end{array}$ & $\begin{array}{c}\tau_{\mathbf{0}} \text { slump test } \\
\mathbf{( P a )}\end{array}$ & $\begin{array}{c}\tau_{\mathbf{0}} \mathbf{r} / \tau_{\mathbf{0}} \mathbf{s} \\
\text { ratio }\end{array}$ \\
\hline 95.5 & 1.4 & 27.8 & 284.0 & 21.3 & 13.4 \\
\hline 101.8 & 1.5 & 26.5 & 243.0 & 19.5 & 12.5 \\
\hline 109.0 & 1.6 & 25.2 & 194.0 & 16.6 & 11.7 \\
\hline 115.3 & 1.7 & 24.2 & 145.0 & 10.3 & 14.1 \\
\hline 121.9 & 1.8 & 23.1 & 118.0 & 7.1 & 16.6 \\
\hline
\end{tabular}

It is interesting to notice that slump tests results are significantly smaller than rheometers, with an average difference ratio of 13.6 (Table 4). This finding is in agreement with the statement that by reducing friction surface effects in the slump test, as it has been done through lubrication of the soil-cone contact and rapid uplift of the cone, smaller yield stresses can be measured in the slump test (Roussel \& Coussot [9]).

As the flow mechanism of the material in the slump test approaches better the one developed by the moving mass of a debris flow, it has been suggested a correction from the rheometer to the slump test results, as it is shown in Figure 8. Investigations are being taken in PUC-Rio to provide better understanding of yields stress measurement in the slump test.

Figures 9 and 10 shows the variation of yield stress with water content and solid concentration, respectively. As expected, it is observed, in both methodologies, the higher is the water content (lower solid concentration), the lower is the yield stress observed in the material. This observation indicates that water content rise reduces the flow resistance of the soil mass, in an exponential relation.

In Figure 10 it is shown a comparison between results herein obtained and data from di Santilo et al., O'Brien \& Julien and Coussot \& Piau [3,5,7]. di Santilo et al. [3] analysed the yield stress of three pyroclastic soils in a rotation rheometer using a vane geometry. O'Brien \& Julien [5] studied natural mudflow materials in a concentric cylindrical rotational viscometer. Finally,
Coussot \& Piau [7] analysed different debris flow materials in a parallel plate rotational rheometer.

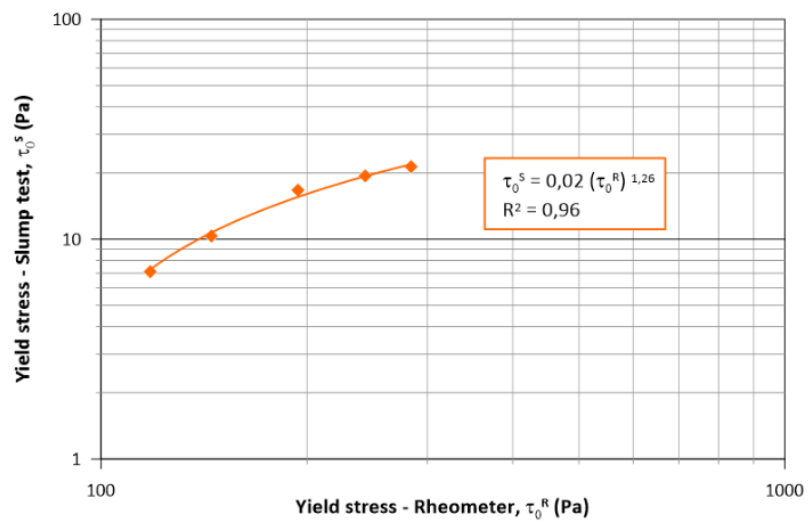

Fig. 8. Proposed correction from rheometer to slump test results.

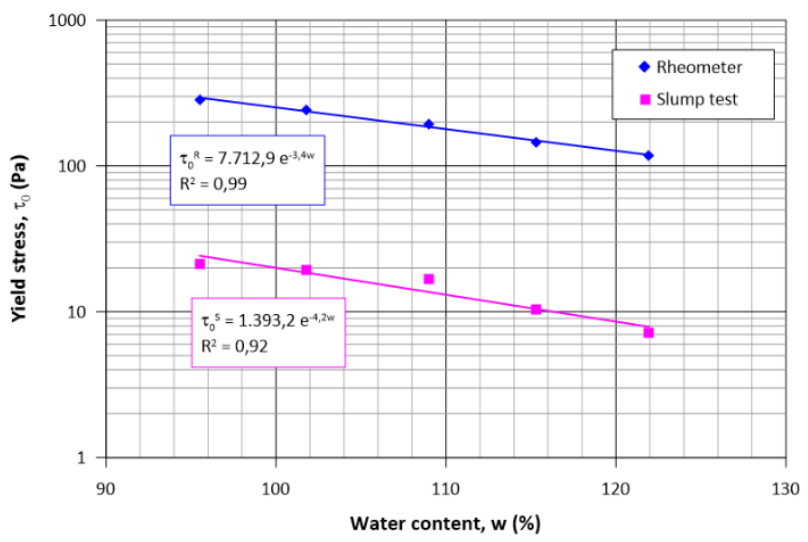

Fig. 9. Variation of yield stress with water content.

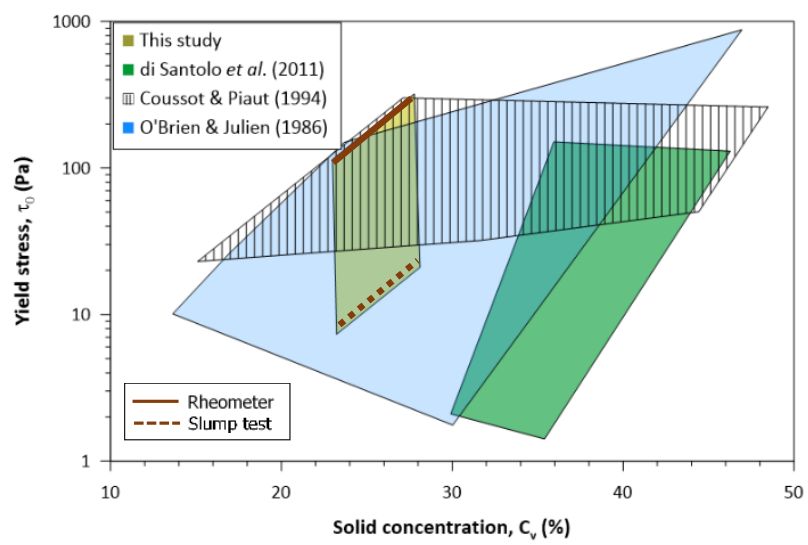

Fig. 10. Comparison between this study and literature results from experiments in soil materials.

The author's results are in quite good agreement with data from this study, which can be observed in the superimposition of regions presented in Figure 10, leading to the statement that the slump test is an efficient and cheap alternative methodology for soils yield stress measurement, once the test leads to similar results compared to expensive rheometric equipment, such as rheometers and viscometers. 


\section{Conclusions}

The yield stress of a tropical colluvium from Rio de Janeiro/Brazil has been studied through two different methodologies: a traditional rotational rheometer and a modified set-up of the slump test.

Sedimentation tests with deflocculant and with water indicates that the fine fraction of the soil form silty to fine sand particles in presence of water, stating that highly laterizated soils may present flow properties which are not related to its real grain size distribution, since those properties are known to be related to that distribution.

Flow curves of the material were obtained in sweep tests realized in a parallel plate geometry in the rheometer and yield stresses were determined in acceleration and deceleration ramps. Hysteresis effects have found to be negligible when comparing the two processes, and the less significant the higher is the water content. This finding indicates that may not occur significant changes in water content or solid concentration during the movement of the soil-water mass downhill during debris flow events.

The slump tests were performed in a way to minimize surface friction effect in the cone-soil contact, what enabled the measure of lower yield stresses in those tests. Furthermore, rheometer results are found to be significantly higher when compared to slump test results. Considering the slump test more representative of a soilwater mass flow downhill, it has been suggested a correction from the rheometer tests to the slump tests.

The analysis of yield stress variation with respect to water content or solid concentration indicates that increments on the water content provides an exponential decay of flow resistance of the material, pointing out an influence of intense rain events and debris flow triggering.

A comparison between data from this study and from the literature has been established. All results are related to soil-water samples, from different origin world abroad. It is noted a common region of variation of yield stress and solid concentration when comparing all the studies. This observation states the slump test is a fairly good methodology to yield stress measuring.

\section{References}

1. T. M. P. de Campos, \& M. S. V. Galindo. Géotechnique 66, No. 7, 533-545. (2016)

2. S.W Jeong. J. Mountain Sci. 11, No. 1, 31-40. (2014)

3. A. Scotto di Santolo, A. M. Pellegrino, A. Evangelista, \& P. Coussot. Géotechnique 62, No. 1, 19-27. (2012)

4. Jeong, S. W. Geosci. J. 14, No. 4, 359-369. (2010)

5. J. S. O'Brien. \& P. Y. Julien. J. Hydraulic Engng 114, No. 8, 877-887. (1988)

6. M. S. V. Galindo. MSc dissertation, Pontifícia Universidade Católica do Rio de Janeiro, Brazil (in Portuguese). (2013)

7. P. Coussot, \& J.-M. Piau. Rheol. Acta 33:175-184. (1994)
8. S. W. Jeong. Geosciences Journal. 17, No. 3, 241247. (2013).

9. N. Roussel, \& P. Coussot. J. Rheol. 49(3), 705-718. (2005) 